sciforum,

\title{
Evaluation of the in vitro production of exopolysaccharides by fluorescent Pseudomonas isolated from clay soil contaminated with hydrocarbons in the Ecuadorian Amazon.
}

\author{
González-Sacoto $^{a}, J_{.,}$Estrella $^{a}$, M., Astorga ${ }^{a}$, D., Hidalgo ${ }^{b}$, D., Lopez ${ }^{b}$ J., Yánez $^{b}$ P., \\ Urvina $^{b}$, J. y Luna ${ }^{a}, V$. \\ ${ }^{a}{ }^{1}$ Pontificia Universidad Católica del Ecuador, Facultad de Ciencias Exactas y Naturales, Quito, \\ Ecuador. \\ ${ }^{b}$ PETROAMAONAS EP, Centro de Investigación de Tecnologías Ambientales, Joya de los Sachas, \\ Ecuador.
}

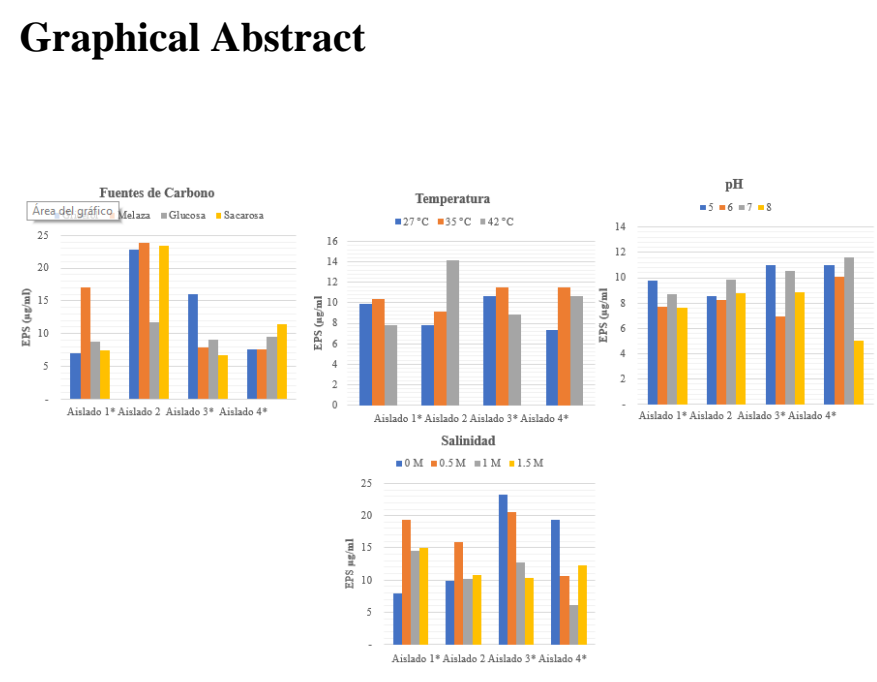

\begin{abstract}
.
Soil is an essential natural resource for life, which has been affected by economic activities such as oil exploitation [1]. Around one million cubic meters of soil contaminated with hydrocarbons from the Ecuadorian Amazon has been bioremediated through the "Amazon Live" Project of PETROAMAZONAS EP. However, the clay soil, characteristic of the Ecuadorian Amazon, is compacted and generates moisture and oxygenation problems, which constitutes an adverse environment for the development of microorganisms [2]. Among the adaptive mechanisms are the production of exopolysaccharides (EPS), compounds generated by many microorganisms in response to hostile environmental conditions. The EPS can interact with clay particles to form micro and macroaggregates of soil and, therefore, increases water retention and reduces desiccation [3]. Precisely, fluorescent bacteria of the genus Pseudomonas are commonly found in soils contaminated with hydrocarbons and can form protective biofilms, mostly composed of EPS [4].

Four fluorescent isolates were recovered from clay soil samples, which were phenotypically characterized by colonial morphology, fluorescence under UV light, Gram staining and oxidase and catalase tests. Soon, biochemical
\end{abstract}


identification with API 20 NE will be carried out, and molecular confirmation through the analysis of 16S rRNA. The isolates were used to produce EPS with different carbon sources. A King B Agar base was used and the $2 \%$ carbon source (glycerol, glucose, sucrose and molasses) was added. The abiotic stress conditions were carried out in King B broth with glycerol and adjusted to the respective stress conditions: salinity $(0 \mathrm{M}, 0.5$ $\mathrm{M}, 1.0 \mathrm{M}$ and $1.5 \mathrm{M}), \mathrm{pH}(5,6,7$ and 8$)$ and temperature $\left(27^{\circ} \mathrm{C}, 35^{\circ} \mathrm{C}\right.$ and $\left.42^{\circ} \mathrm{C}\right)$. A 0.5 McFarland concentration of each isolate was inoculated and incubated for 72 hours at $27^{\circ} \mathrm{C}$, except in the temperature experiment. EPS extraction was performed with glass beads, $96 \%$ cold ethanol and centrifugation. All treatments of each experiment were performed in triplicate. The quantification of EPS was carried out by the modified phenol-sulfuric acid method of Dubois, after performing a glucose calibration curve.

Based on the results obtained, a one-way analysis of variance (ANOVA) was performed. Isolates 1 and 2 produced a higher amount of EPS with molasses, isolate 3 with glycerol and isolate 4 with sucrose as a carbon source. In terms of temperature, isolates 1, 3 and 4 produced a greater amount of EPS between $27-35^{\circ} \mathrm{C}$, while isolate 2 at $42^{\circ} \mathrm{C}$. According to the $\mathrm{pH}$, the best production was observed at a neutral and slightly acidic $\mathrm{pH}$. Finally, regarding salinity, it was observed that isolate 1 and 2 produced a higher amount of EPS at a concentration of $0.5 \mathrm{M}$ sodium chloride, and isolate 3 and 4 with $0 \mathrm{M}$ sodium chloride.

The results show that EPS production is influenced by the source of carbon and environmental conditions. The best performance in EPS production is obtained at least under an abiotic stress condition. These changes represent adaptive changes of bacteria against conditions of abiotic stress. Their tolerance depends on the fact that these microorganisms can be used in the improvement of the clay soil structure to favor bioremediation processes in the Amazon. 


\section{References}

[1] Velásquez, J. "Contaminación de suelos y aguas por hidrocarburos en Colombia. Análisis de la fitoremediación como estrategia biotecnológica de recuperación”. Revista de Investigación Agraria y Ambiental. 2017. Vol. 8.

[2] Phillips, T. "Bioremediation: using living organisms to clean the environment". The Balance. 2017. [3] Gupta, V.V, Germida, J. J. "Soil aggregation: Influence on microbial biomass and implications for biological processes". Soil Biology and Biochemistry. 2015.

[4] Sandhya, V, Ali, S. "The production of Exopolysaccharide by Pseudomonas putida GAPP45 under Various Abiotic Stress Conditions and Its Role in Soil Aggregation”. Microbiology. 2015. Vol. 84, p. 512-519.

[5] Madigan, M.T, Martinko, J.M, Bender, K.S. “Biología de los microorganismos”. 2015. 